\title{
Cost management and Control Research Based on The Case of the Tobacco Enterprise Distribution Center
}

\author{
Zhongzheng WANG \\ Jilin Agricultural Science and Technology College, Jilin, China
}

\begin{abstract}
Tobacco enterprise distribution center is the logistics institution of tobacco enterprise. Under the function of many factors, cost management of tobacco enterprise distribution often caused an increase in the enterprise management cost. This paper analyzes the main factors affecting the cost management and control of a tobacco distribution center. On this basis, summarizes four principles of management and control and propose the specific methods of scientific controlling distribution cost to the distribution center.
\end{abstract}

KEYWORD: tobacco distribution center; logistics; cost management; control

\section{INTRODUCTION}

Institute of forward-looking industry released "20142018 Foresight and investment strategic analysis report in China tobacco logistics industry market" analyzed[1]: Tobacco industry logistics construction is still in its infancy and is faced with many difficulties. To achieve tobacco from traditional state to modern state, both hardware and software need to be upgraded. From the current development situation of the Jilin tobacco distribution center, improving enterprise management refinement level and actively strengthening the management and control of tobacco logistics distribution cost are important means for the tobacco companies to reduce logistics cost and improve the core competitiveness.

\section{STRUCTURE OF THE COST OF A CERTAIN TOBACCO DISTRIBUTION CENTER}

Mainly include the basic management cost (the depreciation of fixed assets, staff salaries, office costs) and logistics cost of daily management[2]. Compared with the relatively stable management cost, logistics cost is a main factor affecting the profitability of tobacco enterprises distribution center. According to the process of tobacco products distribution parts, it can be divided into six big types including the transportation cost, storage cost, loading and unloading cost, packaging cost, rework cost and delivery cost[2]. Management and control of tobacco enterprise distribution center cost is for this six kinds.

\section{ANALYSIS OF THE BASIC OPERATION MODE OF TOBACCO ENTERPRISE DISTRIBUTION CENTER}

\subsection{Basic mode}

Tobacco enterprise distribution center is a product logistics agency centered on tobacco enterprise's product warehouse. The agency in the terminal market for products distribution business mainly depends on transit station.

From the point of distribution center operation mode that warehouse don't face consumers and only supply retailers with sources facilitates the distribution of tobacco products in the terminal market and improves the distribution speed of tobacco companies.

\subsection{The specific distribution mode}

Because the tobacco product sale policy and area sale policy influence each other, here following are two kinds of distribution way: 1. directly deliver products to retailers from the warehouse according to the orders; 2 . through tobacco enterprise designated business personnel, tobacco products can also be carried from transit warehouse or even total tobacco warehouse of total enterprise tobacco distribution center. There are four main distribution modes of tobacco enterprise distribution center[3]: ONE: the direct way. Tobacco retailers through the distribution center send the purchase orders and receive products directly from the warehouse or general warehouse and distribute to retailers. (as shown in Fig. 1) 


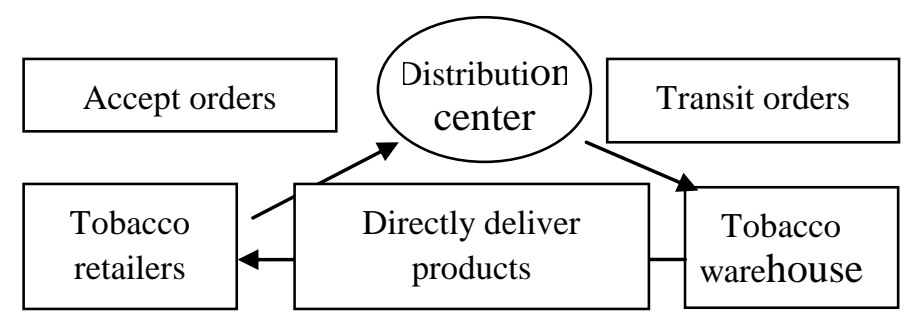

Figure 1: The direct type for tobacco product distribution pattern

TWO: the concentrated way. Tobacco retailers send the purchase orders to distribution center and distribution center will arrange tobacco company sales staff to concentrate products from multiple transit warehouses and distribute to tobacco retailers. (as shown in figure 2)

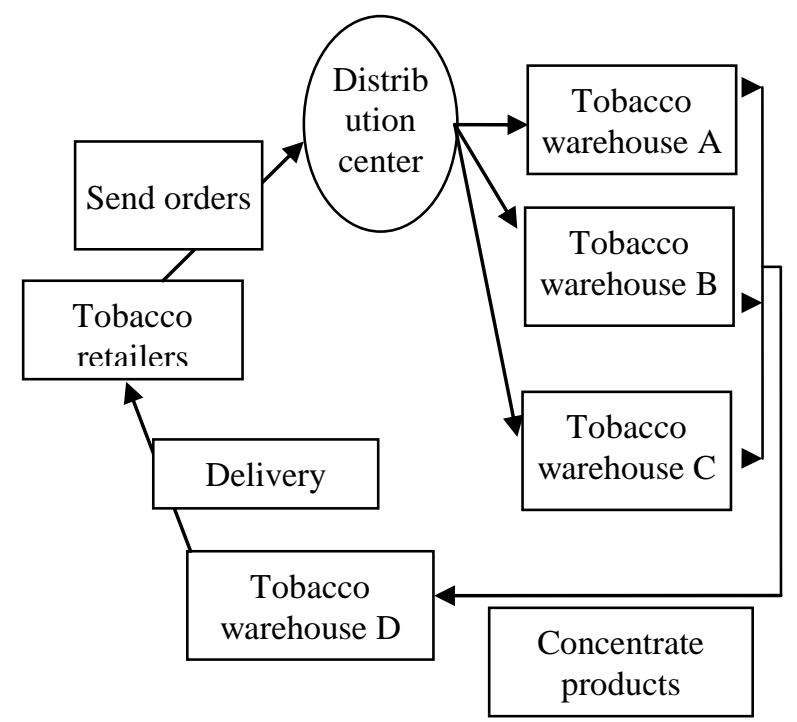

Figure 2: The concentrated type for tobacco product distribution pattern

THREE: the scattered way. Tobacco retailers send the purchase orders. Tobacco company sales staff directly distribute products to them from the various transit warehouses through a closed carriage and load goods from a supplier or distribution node to multiple clients. (as shown in Fig. 3)

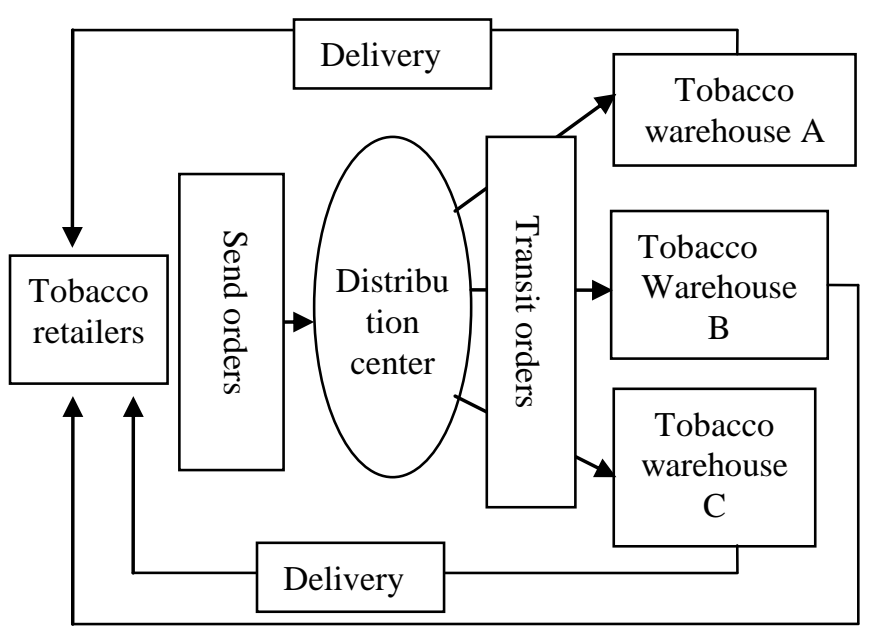

Figure 3: The scattered type for tobacco product distribution pattern.
FOUR: mixed way. To be simply, distribution center receive tobacco retailer orders and arrange warehouses distribute in the concentrated and the scattered way.

\section{THE MAIN FACTORS AFFECTING THE COST MANAGEMENT AND CONTROL OF TOBACCO ENTERPRISES DISTRIBUTION CENTER}

From the perspective of the operation management mode of tobacco distribution center, main factors affecting the cost management and control of the tobacco enterprise distribution center represent in the following four aspects:

\subsection{Orders}

The tobacco terminal products market delivery is based on the costs of distribution. From the perspective of the distribution value of tobacco products themselves, only the large single orders are worth direct distribution[2]. Because the greater the amount of single orders are, the scale effect is more obvious, the single orders shipping costs will be lower.

\subsection{Distribution distance}

The shorter the distribution distance from the warehouse to terminal retailers is, the tobacco product delivery time's cost and transportation's cost will be lower. Otherwise they will be higher.

\subsection{Transit warehouse scale}

Transit warehouse belonging to distribution center is the closest warehouse near market terminal retailers. From the point of actual sales, it is difficult to achieve in some remote markets that tobacco products are delivered from the general tobacco distribution warehouse directly to tobacco market terminal retailers. So the construction of transit warehouse is very necessary. But the transit warehouse construction scale itself may also affect the entire distribution cost of the area market. For example, building a transit warehouse of $14 \%$ market capacity at the market of $30 \%$ sales capacity will be bad for the supply control of products distribution; Conversely, it will also lead to the rise of storage management cost because of the product backlog if building a transit warehouse of $20 \%$ market capacity at the market of $12 \%$ sales capacity. So choosing the right warehouse size is a question worth discussing. 


\subsection{Distribution lines}

Wherever to realize products logistics between the general warehouse and transit warehouse or realize the product circulation between the transit warehouse and the terminal retailers' actual locations, selection of suitable distribution line suitable is very necessary. As for the tobacco enterprises, nation has hard restrictions for sale of tobacco products. Every year cigarette sales is limited by the nation.

\section{THE SPECIFIC METHODS FOR TOBACCO ENTERPRISE DISTRIBUTION CENTER SCIENTIFICALLY CONTROLLING COST}

\subsection{Optimized design the specific path of logistics distribution}

From the whole process of distribution of tobacco products, being uncertain about delivery method of specific tobacco products is an important reason resulting in logistics cost management losing control in terminal transport market. Try to use integrated clustering analysis priority method to classify customer, and then use the improved genetic algorithm with control switch system to solve the multi-objective optimization method of the VRP to construct a random switch, thus increasing the diversity of sales path, adhere to the "convenient, accurate, timely, efficient and economical" basic principles. Make it clear that which mode of transportation the tobacco products should take from the center to the warehouse to the sales terminal, which specific lines, which stop, how much fuel costs for transfer and so on.

\subsection{Strictly limit the warehouse inventory levels}

For tobacco enterprise distribution center, the faster the tobacco products flow, the shorter the tobacco enterprise's profit cycle. It also means the promotion of profitability for tobacco enterprise product. Stagnation of tobacco products' circulation means that products which originally shall create profits become "white elephants" of increasing management cost instead. Fundamentally, transit warehouse inventory should be appropriate. In other words, product sales in terminal retailers should be continuous.

\subsection{Prior to personnel management, form energy- efficient enterprises organizational culture}

As for the problems that internal members of tobacco industry enterprise thoughts are diversified, with the help of the third party training institutions, design effective training contents, make the "energy saving" become all the staff working faith from the distribution center to the logistics management of tobacco products department. Proceed cost control of the whole tobacco products distribution system, enhance employee awareness of economy and thrifty ability, form the enterprise culture of "saving the cost, high quality and efficient".

\subsection{Selective use of third party logistics enterprises}

Adopt optimization algorithm. As for this improving product logistics cost of enterprise distribution and affecting the profit, use highly developed modern third party logistics industry to realize fast delivery of products. Affecting factors of adopting the third party logistics distribution as shown in the figure below:

Table 1 The impact factor of the logistics option

\begin{tabular}{|c|c|c|c|c|c|c|}
\hline Logistics selection & Retailer number & Product type & Monthly sales & Personnel costs & Fuel costs & Total \\
\hline This enterprise & & & & & & \\
\hline The third party logistics & & & & & & \\
\hline
\end{tabular}

Through calculation, when all the total logistics cost of the enterprise is beyond the situation of third party logistics price, this enterprise can choose the professional logistics channel.

\subsection{Set up scientific and reasonable weight inspection system}

In modern logistics enterprise, realizing analysis of facts with measurable data is more scientific, reasonable than textual, ambiguous expressions. Of course, this system can be modified and improved according to the enterprise's actual use in order to satisfy the actual different situation of the enterprises. 
Table 2 Scientific and reasonable weight inspection system

\begin{tabular}{|c|c|c|c|c|c|c|}
\hline $\begin{array}{c}\text { Level one } \\
\text { index }\end{array}$ & Weight & Level two index & Weight & Evaluation target & $\begin{array}{c}\text { Score of } \\
\text { level one }\end{array}$ & $\begin{array}{r}\text { Score of } \\
\text { level two }\end{array}$ \\
\hline \multirow{3}{*}{ costs } & & Single route & & $\leqslant$ exact standards & & \\
\hline & & Logistics cost per hour & & $\leqslant$ exact standards & & \\
\hline & & Average cost & & $\leqslant$ exact standards & & \\
\hline \multirow{4}{*}{ staff } & & Rate of loss & & Below the industry average & & \\
\hline & & Salary standard & & Not below the industry average & & \\
\hline & & Employment norm & & Reasonable employment & & \\
\hline & & Personnel qualifications & & Post requirements & & \\
\hline \multirow{2}{*}{$\begin{array}{c}\text { Customer } \\
\text { satisfaction }\end{array}$} & & External satisfaction & & Company inspection standard & & \\
\hline & & Internal satisfaction & & Company inspection standard & & \\
\hline \multirow{5}{*}{$\begin{array}{l}\text { Internal } \\
\text { inspection } \\
\text { standard }\end{array}$} & & Service level & & Industry standard & & \\
\hline & & Communication solution rate & & Industry standard & & \\
\hline & & average communication time & & Industry standard & & \\
\hline & & Effective communication rate & & Industry standard & & \\
\hline & & Other indicators for each item & & Industry standard & & \\
\hline Total & & & & & & \\
\hline
\end{tabular}

\subsection{Establish an effective cost control management system of tobacco enterprise logistics}

On the one hand, according to the local general logistics cost of tobacco logistics enterprise, adjust measures to local conditions, formulate cost standard of tobacco products distribution logistics, unify accounting caliber and accounting process of logistics link's cost, establish and improve the system of appraisal cost of. On the other hand, around the tobacco enterprise distribution center set up perfect cost evaluation system, establish continuously effective cost management mechanism of rewards and punishment. Through the appropriate incentive system, guide people to restrain their own behaviors. Influence and change the enterprise staff's understandings of job responsibility. Equal the cost management and the income level for each person.

\section{CONCLUSION}

Through the research and analysis, under the guidance of the four principles of scientific management of tobacco enterprise cost in distribution center, setting scientific and reasonable weight inspection system; optimizedly designing the specific path of logistics distribution; strictly limiting the warehouse inventory level; selectively taking use of the third party logistics enterprises; being prior to personnel management, forming energy-efficient enterprises organizational culture; establishing an effective cost control management system of tobacco enterprise logistics can all effectively improve the cost management and control of level tobacco enterprise distribution center.

\section{REFERENCES}

[1] Yuhui Wu, The present situation and measures of the application of the tobacco enterprise target cost management, Commercial accountant, 2013. 05.

[2] Xiangxin Pan, The thinking about cost control of distribution center, Logistics engineering and management, 2013. 08.

[3] Feng Wei, Logistics cost control of distribution center, Logistics engineering and management, 2013.06. 